\title{
JOSÉ OSÓRIO DE OLIVEIRA E SUAS REFLEXÕES SOBRE A “MODERNA” LITERATURA BRASILEIRA
}

Raquel S. Madanêlo Souza ${ }^{1}$

Resumo: O objetivo deste texto é refletir sobre o conceito de literatura brasileira na obra do intelectual português José Osório de Oliveira, e sobre seu papel na divulgação dessa mesma literatura, no âmbito das relações luso-brasileiras e do intercâmbio que ele se propôs a estabelecer e incentivar entre Brasil e Portugal - principalmente - a partir nas décadas de 30 e 40, do século XX.

Palavras-chave: José Osório de Oliveira; intercâmbio luso-brasileiro; literatura; crítica e historiografia literárias

\section{José Osório de Oliveira and his reflections on the "modern" brazilian literature}

Abstract: The purpose of this paper is to reflect on the concept of Brazilian literature in the intellectual work Portuguese José Osório de Oliveira, and on its role in the dissemination of that literature within the Luso-Brazilian relations and exchange he proposed to establish and encourage between Brazil and Portugal - mostly - from the 30s and 40s of the twentieth century.

Key-words: José Osório de Oliveira; Luso-Bazilian interchange; literature; reviews and literary historiography

\footnotetext{
${ }^{1}$ Professora de Literatura Portuguesa da Universidade Federal de São Paulo (UNIFESP). Esse texto é fruto de uma pesquisa desenvolvida em Portugal, com financiamento da FAPESP (BPE).
} 
É a língua, e a literatura, portanto, o que conserva, através dos séculos, os traços das civilizações. (OLIVEIRA, 1931).

Tudo quanto tenho escrito sobre a literatura brasileira poderia ser considerado como memórias de uma amizade! Tudo, até mesmo aquilo que tenho escrito sobre os_escritores do passado, até mesmo aquela História Breve, em que tentei uma síntese da evolução da literatura brasileira! Porque, na verdade, tem sido sempre o resultado de uma amizade humana e pessoal com as coisas e a gente do Brasil. (OLIVEIRA, 1942).

José Osório de Oliveira foi um crítico, escritor, tradutor, ensaísta e cronista português nascido em Setúbal, em 1900, que morreu em Lisboa em 1964; filho da conhecida escritora, pedagoga e defensora dos direitos da mulher, Ana de Castro Osório e do poeta lusitano Paulino de Oliveira. Era irmão do também escritor João de Castro Osório; casou-se em 1930 com a cantora lírica Raquel Bastos, ao lado de quem viveu e dedicou a vida a refletir sobre Literatura e Cultura Brasileiras, Portuguesas e da África de Língua Portuguesa.

Segundo o crítico David Mourão Ferreira, em seu livro Hospital das letras, José Osório de Oliveira foi "homem de dúvida, não menos, foi homem de fé (...) sobretudo no valor e nos poderes da literatura”. Já João Bigotte Chorão, em “O drama de João de Castro Osório" (1998, p. 76), afirma que:

José Osório de Oliveira, irmão de João de Castro Osório, me parece literariamente mais feliz, com a sua clara prosa de sobriedade clássica. Ensaísta e crítico literário, o neogarretiano autor d'O romance de Garret, praticava também uma literatura de ideias, como se pode ver no muito recomendável livro Psicologia de Portugal, onde o pensamento não se divorcia do sentimento ou do que ele chama 'conhecimento emotivo'. Logo na página de abertura desse livro, declara o autor: 'Não sou nacionalista porque não creio que povo algum seja absolutamente superior aos outros e tenha recebido qualquer missão que o autoriza a impor a sua vontade'. Eis uma declaração que não subscreveria o seu irmão João de Castro Osório, o qual acreditava na missão providencial de um povo - o povo português.

Neste sentido, sua reflexão sobre Portugal e sua reflexão sobre o Brasil e sobre Cabo Verde são sempre constituídas e permeadas por uma junção entre o pensamento racional e a emotividade diante do texto literário, partindo de sua experiência pessoal e afetiva com o objeto analisado, com o meio e as pessoas.

Da produção bibliográfica desse escritor constam mais de 50 livros publicados, por diferentes Casas Editoriais. Produziu ainda muitos estudos que se encontram dispersos (em periódicos) - grande parte deles incidindo sobre a Literatura Brasileira. 


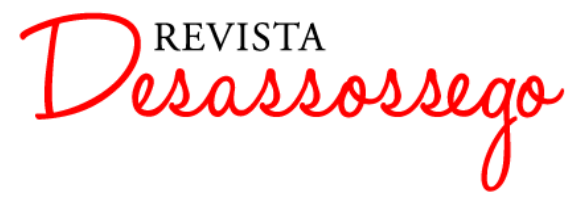

DESASSOSSEGO $13 \quad$ JUN/2015 | ISSN 2175-3180

DOI: http:/ /dx.doi.org/10.11606/issn.2175-3180.v7i13p100-108

Seu primeiro livro, chamado Literatura brasileira, foi publicado em 1926 e contava com um prefácio de Carlos Malheiro Dias. Osório escreveu a primeira História breve da literatura brasileira, em Portugal, cuja $1^{a}$ edição foi publicada em 1939. De vocação liberal e de tendência republicana, assim como o pai, Paulino de Oliveira, conforme depoimento do Prof. Arnaldo Saraiva $^{2}$, manteve diálogo com escritores e intelectuais que podem ser considerados representativos de diferentes - e até mesmo opostas - tendências ideológicas e políticas, como é o caso do monárquico integralista, António Sardinha; e do racionalista republicano, António Sérgio. No caso brasileiro, conviveu com intelectuais como Plínio Salgado, Sérgio Buarque de Holanda, Gilberto Freyre e Rui Ribeiro Couto.

Parte do espólio depositado na Biblioteca Nacional de Portugal e do acervo bibliográfico que se encontra no Depósito da Biblioteca da Faculdade de Letras, da Universidade de Lisboa, revelam o diálogo desse escritor com o Brasil e o seu interesse pela sua literatura. Os livros ali depositados fornecem informações fundamentais sobre essas relações - tanto do ponto de vista da biografia intelectual do escritor estudado, quanto do ponto de vista literário e político das relações entre as duas nações em questão. Este acervo, em que constam algo em torno de 300 livros (a grande maioria de crítica e de Literatura Brasileiras), teria pertencido ao Instituto de Filologia Românica e ao Instituto de Cultura Brasileira (ambos institucionalizados na FLUL em 1961, conforme foi verificado nas Atas do Conselho de Graduação daquela Instituição).

E apesar do grande empenho de Osório de Oliveira em mediar as relações entre Portugal e Brasil na primeira metade do século XX e de ter sido ele um dos mais importantes e esforçados divulgadores da literatura brasileira em terras lusitanas, o que notamos hoje é a quase inexistência de estudos de fôlego sobre a obra desse intelectual português.

\section{José Osório de Oliveira e a Literatura brasileira}

Os ensaios e críticas de José Osório sobre a literatura principiam, de modo geral, por um breve introito em que o escritor se coloca subjetivamente diante do objeto que vai analisar: "Assim como não posso separar do meu juízo de crítico a minha impressão de leitor,

\footnotetext{
${ }^{2} \mathrm{O}$ prof. Arnaldo Saraiva foi entrevistado por mim no mês de dezembro, no Porto. Suas informações contribuíram para a reflexão sobre a história da relação de José Osório com os escritores brasileiros da modernidade.
} 


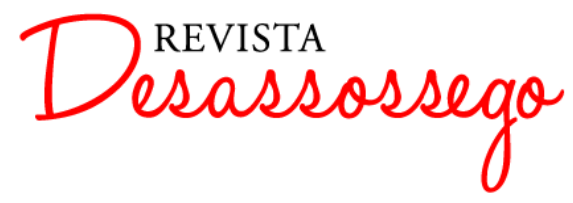

DESASSOSSEGO 13 | JUN/2015 | ISSN 2175-3180

DOI: http://dx.doi.org/10.11606/issn.2175-3180.v7i13p100-108

ao apreciar uma obra, vejo-a, por um lado, com a razão, por outro com a sensibilidade" (OLIVEIRA, 1926, p. 4).

Em seu primeiro livro sobre a Literatura brasileira, de 1926, o ensaísta já apontava para a ligação pessoal - biográfica e afetiva - com essa literatura:

Desde garoto que estou em contato com livros brasileiros. Na educação sentimental da minha infância tiveram papel preponderante os livros de Bernardo Guimarães, o autor de $A$ escrava Isaura, tão denegrido pela geração que hoje ergue, pela pena de Mário de Andrade, o estandarte de A escrava que não é Isaura. Como um brasileiro, ri com $A$ moreninha de Manoel de Macedo e comovi-me com o Ubirajara, com a Iracema e com $O$ Guarani de Alencar e com a inocência de Taunay. Depois veio Aluísio com O homem; depois, quase todo o Machado de Assis; depois, Euclides com Os sertões. (OLIVEIRA, 1926, p. 4).

Já neste ensaio da juventude, é possível perceber como o escritor pensa e analisa a produção literária do Brasil a partir da afetividade, de sua história pessoal ${ }^{3}$, a saber, o fato de ter passado parte da juventude em São Paulo, com seus pais, a escritora Ana de Castro Osório, o poeta Paulino de Oliveira e também com o irmão, João de Castro Osório. Para além desse dado biográfico e pessoal, é preciso notar que Osório já apresentava neste texto, publicado em 1926, a ideia de "livros brasileiros" e de Literatura brasileira, distinguindo ali, em suas apreciações, a produção literária do Brasil desde o século XIX. Além disso, o que se nota é que José Osório foi um crítico do seu tempo que olhou criticamente a literatura desse tempo. Observe-se, por exemplo, a visão do autor sobre o livro e a influência de Mário de Andrade e sua “geração” em relação à obra de Bernardo Guimarães. Neste trecho, Osório já evidenciava nessa conexão o papel de negação - "não" - do passado, em que se teria empenhado a "geração" que seria, segundo ele, liderada por Mário.

A redação de seu primeiro livro parece ter sido motivada pela famosa conferência de Graça Aranha, na Academia Brasileira de Letras em 1924, “O espírito moderno”. Essa conferência, que incitou respostas diversas de outros intelectuais, como se pode verificar por exemplo na revista carioca Terra de Sol (1924-1925), foi o que compeliu Osório a elaborar o estudo de 1926. Para além de um crítico atento ao seu tempo, que segue nesse ensaio pensando a Literatura Brasileira, é importante compreender como o escritor português definia a literatura brasileira em seu primeiro livro dedicado a ela:

\footnotetext{
3 “Autodidacta que teve por única escolaridade as curiosidades pessoais e as solicitações do ambiente, desde o terno e cultíssimo meio familiar às atrações do convívio citadino, incerto e vário, salvo na aceitação dócil do meridiano intelectual" (CARVALHO, 1931, p. XI).

4 "A paixão da negação" (COMPAGNON, 1996).
} 
E qual a razão desse fenômeno, se a literatura brasileira, desde sempre, viveu livre de qualquer tutela da metrópole? A afirmação de Graça Aranha de que 'Rompendo com o classicismo português, Alencar afirmou a independência intelectual do Brasil' é uma diminuição da sua glória. Não, o 'Guarani' não é 'o grito do Ipiranga da literatura brasileira'. Colônia durante três séculos, o Brasil foi, desde sempre, pela sua literatura, uma nação. O 7 de Setembro não foi mais do que a sanção política do que era há muito uma realidade sob o ponto de vista literário. Porque a diferença entre duas literaturas tais como são a portuguesa e a brasileira não está, não pode nem deve estar na língua que é comum mas no espírito e na emoção que são diversos. E, falte-me embora autoridade para tudo mais, que são diversos posso eu dizê-lo porque conheço a literatura brasileira e basta tê-la lido para o poder dizer. (OSÓRIO, 1926, p. 19-20)

Essa longa citação tem o objetivo de mostrar como nesse primeiro ensaio, Osório estabelece um debate direto com o texto da citada conferência de Aranha, e como busca desvincular a "existência" da Literatura Brasileira de sua relação de dependência, ou independência, da metrópole portuguesa. Para ele, a língua seria a mesma, mas o "espírito" e a "emoção" seriam diversos, o que seria suficiente para confirmar a existência de livros brasileiros e, por consequência, de uma literatura brasileira.

Na sequência deste livro, Osório publicaria Geografia literária, em 1931, que trazia um texto em que ele retomava o ensaio de 1926 e buscava rever algumas das ideias defendidas anteriormente. No artigo "A literatura brasileira contemporânea", retirado de Geografia, Graça Aranha é referido como a "personalidade literária mais discutida no Brasil". Neste novo ensaio, Osório defende-se e desculpa-se pela imaturidade de seu livro anterior.

Já Espelho do Brasil, de 1933, é iniciado com um "Prefácio sentimental” em que o autor descreve as memórias da sua infância, filho do "cônsul de Portugal" 5 , indo fardado celebrar a Independência do Brasil. O ensaio "Um romance do Brasil", deste mesmo livro, começa, assim, com Osório pensando o Brasil a partir de Portugal: "Um país é uma coisa muito complexa para caber dentro de um romance". E isso, para dizer que apesar de a crítica lusitana creditar à Ilustre Casa de Ramires uma representação quase alegórica de Portugal, ela o faria sem dar a conhecer e destacar as especificidades de cada região daquela nação. O ensaísta retoma o Canaã, de Graça Aranha, para avançar e apontar para a diversidade dos romances brasileiros. Sua reflexão se aproxima de discussões daquele tempo, relacionadas a uma espécie de "unidade étnica" brasileira e à formação do povo brasileiro ${ }^{6}$. E é preciso

\footnotetext{
${ }^{5}$ Paulino de Oliveira, pai de Osório de Oliveira, foi cônsul de Portugal, no Brasil, entre 1911-1914.

${ }^{6}$ Isso que José Osório discute nos anos 1930, era uma discussão muito presente no pensamento da intelectualidade brasileira, por exemplo, na revista Terra de Sol
} 
notar que isso que José Osório discute em seus ensaios dos anos 1930, sobre o Brasil, era também discutido por parte da intelectualidade brasileira, que buscava, assim como ele, uma definição do Brasil, de sua cultura e sua literatura.

E em Brasil, livro tipo catálogo publicado juntamente com João de Barros e Gastão de Bettencourt, o que se observa é uma mudança na perspectiva crítica do autor em relação à de Literatura Brasileira. Se no livro de 1926, em oposição ao "Espírito moderno" de Graça Aranha, a ideia era a da existência da literatura brasileira independentemente da ligação com a metrópole portuguesa; o que se observa nesse livro de 1938 é que, ao invés de discutir sobre a separação política do Brasil em relação à metrópole portuguesa, como elementos determinantes para a autonomia literária do país, Osório propõe uma subdivisão da literatura em 2 ciclos separados por uma relação de identidade com o meio:

Se fizéssemos a história da literatura brasileira e não este simples ensaio, em vez dessas divisões proporíamos uma outra em dois períodos: aquele em que a literatura é exterior ao meio, descreve a natureza de fora, retoricamente, ou se alheia dela, e não só repete o estilo português como adota, sem muitas vezes adaptar, os caracteres psicológicos e os sentimentos europeus; e aquele outro em que a literatura, identificada com o meio, passa a exprimir, duma maneira brasileira, o que é do Brasil. (OLIVEIRA, 1938, p. 49).

Neste sentido, a identificação com o meio e a descrição desse meio dentro da literatura determinariam a originalidade e a existência de uma literatura autenticamente nacional e independente. Ou seja, a literatura seria nacional somente quando identificada com o meio em que era produzida. Para ele: "na nossa concepção, os períodos literários não correspondem aos períodos históricos: colonial e nacional. Os homens que fizeram a Independência não eram ainda, intelectualmente, brasileiros" (OLIVEIRA, 1938, p. 48). E definir o que é ser brasileiro parece ser uma das preocupações centrais de José Osório em seus discursos sobre o Brasil e sua literatura.

Ainda em busca de determinar o que seria a Literatura Brasileira, Osório discutia a questão da autonomia:

uma literatura só pode dizer-se autônoma quando no gênio nacional encontra uma maneira de ser e de exprimir que a caracterize e distinga de todas as outras; não só, neste caso, da portuguesa, mas, também, da francesa. (OLIVEIRA, 1938, p. 49) 
Neste sentido, o que se observa é que Osório pensava a literatura brasileira de uma perspectiva crítica oriunda da modernidade ${ }^{7}$. Crítico e historiógrafo da literatura, Osório analisava a literatura sua contemporânea pelos princípios dessa modernidade, apontando para a busca da originalidade e da novidade ligadas à ideia de uma possível existência de uma perspectiva autenticamente nacional.

Já na História breve da literatura brasileira, de 1939, o que se observa é uma ampliação do conceito em relação ao livro anterior:

No Brasil, como em todos os países novos, para a literatura ser nacional, e não simples prolongamento das literaturas européias, foi preciso que os escritores preferissem inspirar-se ou obedecer, não à cultura literária, que era estrangeira, mas à cultura no sentido antropológico ou sociológico da palavra, isto é, aquilo que caracteriza o povo brasileiro. É claro que para a formação dessa cultura contribuímos nós poderosamente, como contribuíram o índio e o negro. Mas essa cultura é brasileira, resultado do regime econômico, do sistema de trabalho, da organização social do Brasil, e não produto de importação como a cultura literária. (OLIVEIRA, 1939, p. 16)

Neste livro, surge a noção de "cultura literária" como "produto de importação". E isso também está relacionado à perspectiva de uma crítica que concebia a arte como expressão do novo e do original de um objeto artístico, considerado de maneira comparativa no conjunto das produções de outros países.

Essa que foi a primeira História da literatura brasileira produzida em Portugal, acabou por apresentar uma leitura distinta daquela visão presente no livro de 1926, em seu primeiro ensaio sobre a Literatura brasileira.

\section{Sobre a moderna poesia brasileira}

Retomando Espelho do Brasil, livro de 1933, Osório fala sobre poesia no ensaio “Aspectos da moderna poesia brasileira”, buscando pensar a produção em versos do Brasil de maneira panorâmica: para isso, reflete sobre os poetas da época e busca divulgar a diversidade do país, ao tentar estabelecer uma espécie de "geografia" literária do Brasil. Neste texto, ainda, descreve a diversidade da poesia brasileira, em oposição à ideia de unidade nacional: passa por Oswald, por Mário, por Guilherme de Almeida, Tasso da Silveira,

\footnotetext{
${ }^{7}$ Tomo modernidade no sentido adotado por Otavio Paz em ensaios sobre o tema; e de Compagnon, no livro Os cinco paradoxos da modernidade.
} 
Menotti del Picchia, Ronald de Carvalho, Jorge de Lima, Ribeiro Couto, apontando para a multiplicidade dessa moderna poesia.

Escrevendo sobre escritores de seu tempo, Osório refletiu em suas obras sobre escritores diversos, que faziam parte dos movimentos da época, e a partir de contribuições diferentes para a "moderna" poesia do Brasil. Neste sentido, Osório passou a buscar na literatura que selecionava, em suas antologias, as marcas dessa diversidade do Brasil e da "brasilidade" que ele percebia como elementos distintivos da literatura brasileira.

\section{Conclusão}

Por essa rápida leitura de alguns dos escritos de José Osório, é possível perceber as mudanças na sua maneira de pensar a produção literária do Brasil. Se Osório inicia seu percurso afirmando a existência da literatura brasileira a partir de um embate, indireto, com o discurso de Graça Aranha; em outro momento, passa a refletir sobre a literatura brasileira a partir de critérios não políticos - país dependente ou independente da metrópole -, para considerá-la original quando representativa de elementos ligados ao meio e à natureza nacionais. Nesse sentido, a descrição da natureza, dos costumes, da cultura e de um determinado espaço do Brasil dentro do texto literário passaria a ser critério distintivo e definidor da existência de uma literatura originalmente brasileira. Dessa forma, ele buscou divulgar em seus ensaios e editar em suas antologias os textos literários produzidos no Brasil que mostrassem aos leitores/ouvintes de seus ensaios e suas conferências uma literatura que considerasse singular, quase exótica, a partir de critérios da modernidade estética, e de um olhar estrangeiro, que se quis brasileiro por ordem do afeto.

\section{REFERÊNCIAS BIBLIOGRÁFICAS}

CARVALHO, Joaquim de. "Prefácio". In.: OLIVEIRA, José Osório de. Geografia literária. Editora da Universidade: Coimbra, 1931.

COELHO, Jacinto do Prado. "José Osório de Oliveira, dez anos depois". Revista Colóquio/Letras. Notas e Comentários, $\underline{\text { n. }}{ }^{\circ} 22$, Nov. 1974, p. 80-81.

COMPAGNON, Antoine. Os cinco paradoxos da modernidade. Belo Horizonte: Editora da UFMG, 1996. 


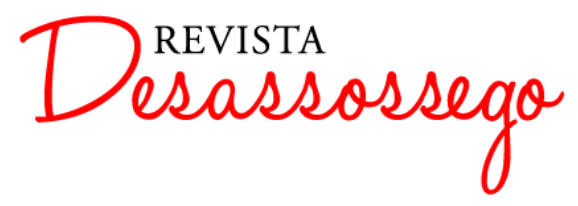

DESASSOSSEGO 13 | JUN/2015 | ISSN 2175-3180

DOI: http://dx.doi.org/10.11606/issn.2175-3180.v7i13p100-108

JARDIM, Eduardo. Os limites do moderno - o pensamento estético de Mário de Andrade. Rio de Janeiro: Relume Dumará, 1999.

MORAIS, Marco António de. "Correspondência portuguesa para Mário de Andrade.

Imagens de Portugal e do Brasil". In: Revista Colóquio/Letras. Documentos, n.. 149/150, Jul. 1998, p. 377-383.

OLIVEIRA José Osório de. Poesia moderna do Brasil. Coimbra: Universidade de Coimbra, Faculdade de Letras, 1942.

OLIVEIRA, José Osório de. A poesia moderna do Brasil. Coimbra: Coimbra Ed.,1942.

OLIVEIRA, José Osório de. BARROS, João de. BETTENCOURT, Gastão de. Brasil. Lisboa: Edições Estampa, 1938 [i.e. 1939].

OLIVEIRA, José Osório de. Espelho do Brasil. Lisboa: Empresa nacional de publicidade, 1933.

OLIVEIRA, José Osório de. Geografia literária. Editora da Universidade: Coimbra, 1931.

OLIVEIRA, José Osório de. História breve da literatura brasileira. Lisboa: Editorial Inquérito, [1939].

OLIVEIRA, José Osório de. Literatura brasileira. Lisboa; Porto: Lumen, 1926. 